\title{
New safeguarding advice for dental teams
}

Dentists and the dental team have been reminded of the importance of making sure practices are fully trained and ready to deal with any issues of safeguarding of vulnerable adults and children in newly issued guidance.

Public Health England (PHE) has issued

Safeguarding in general dental practice, ${ }^{1}$ which provides an overview on the roles and responsibilities of everyone in the dental team in relation to vulnerable adults and children.

The guidance, stresses that dental professionals have an existing 'ethical and legal duty' to act if they believe a patient is being abused, and in this highly sensitive area it helps to be aware of relevant guidance and available support. It also sets out steps to follow in cases of suspected abuse and defines common terminology and different categories of abuse, sets out the legal and regulatory framework, and provides information about training and other resources.

It includes various recommendations for all dental practices to ensure they have proper safeguarding arrangements in place, including:

- Have a practice safeguarding policy that sets out the practice's commitment to protect children and vulnerable patients which should then be regularly reviewed

- Have a named safeguarding practice lead to ensure staff undertake appropriate training and have access to support and advice

- Organise ongoing safeguarding training for both clinical and non-clinical staff that is appropriate for their role

- Have a safeguarding reporting system in place that is known to staff

- Incorporate Safeguarding in general dental practice $^{1}$ as part of the staff induction process to supplement existing safeguarding training

- Discuss the guidance at team meetings and consider how training opportunities and resources can be embedded into the practice.

A section of the guidance is devoted to confidentiality, consent and information-sharing in safeguarding cases, which idemnity providers confirm is a subject that sometimes prompt calls for advise.

A dento-legal adviser for one of the idemnity provders said: 'It makes clear that dental professionals' duty of patient confidentiality is, "not intended to prevent exchange of information between different professionals and staff who have a responsibility for ensuring the protection of children, young people and adults at risk".

'If you're not sure whether safeguarding concerns justify the disclosure of confidential information, the guidance recommends getting advice from the relevant local safeguarding contact.

'In the absence of consent, practices should get advice from their local safeguarding contact or their indemnty provider. Sharing information with the appropriate agencies without consent may be justified if the disclosure is in the patient's best interests or is necessary to protect others from a risk of serious harm.'

It is recommended that dentists keep a record of their decision and the reasons for it - whether it was to share information or not, what information has been shared, with whom and for what purpose.

\section{References}

1. Public Health England. Safeguarding in general dental practice. 3 April 2019. Available at https://www.gov.uk/ government/publications/safeguarding-in-general-dental-practice (accessed April 2019)

\section{New dentistry directors could flesh-out detail on national plan}

The British Dental Association (BDA) in Scotland is hoping that newly appointed dentistry directors for all regions in the country will be able to provide crucial detail on the national oral health improvement plan for north of the border.

The union met with a number of Directors of Dentistry at a recent introductory meeting to discuss a range of issues.

Under the Scottish Government's

Oral Health Improvement Plan (OHIP) ${ }^{1}$ published on 24 January 2018, it promised that it would work with NHS Boards to introduce a Director of Dentistry in each Board area, whose role would be to ensure a strategic approach across primary and secondary care service planning and to focus on oral health improvements within each NHS Board.
NHS Greater Glasgow recently appointed a permanent Chief of Dentistry - Lee Savarrio - and the other NHS Boards have appointed an interim Director of Dentistry.

The Scottish Government has said it anticipates that all substantive Directors will be confirmed by autumn 2019 .

In the meantime, BDA Scotland said it wanted to build effective working relationships and strong communication links with these new Directors.

At the recent introductory meeting, the union and the Directors present discussed various issues, including:

- The roles and responsibilities of the interim Directors

- Funding for the roles

- The Directors' links within NHS Boards

- Communication with Scottish Government
- The initial priorities in the Oral Health Improvement Plan, including local implementation.

The BDA has already raised concerns over the implementation of the Plan and the need for a viable and sustainable plan for dentistry, warning that the Plan is lacking in detail about timescales, outcomes or funding to implement action.

A further meeting with the Directors of Dentistry is to be arranged in the autumn, once permanent appointments have been made.

\section{References}

1. Scottish Government. Oral health improvement plan January 2018. Available at https://www2.gov.scot/ Resource/0053/00530479.pdf (accessed April 2019). 